\title{
Der Rost macht erst die Münze wert!*
}

eder möchte alt werden, aber niemand will alt sein. Dieser unauflösbare Widerspruch reflektiert die Vertracktheit von Gemütslage und Geisteshaltung, wenn es darum geht, sich mit dem Phänomen des Alterns auseinanderzusetzen, das Jean Amery 1966 als „Die unheilbare Krankheit“ bezeichnete.

Für das Altern selbst gibt es keine allgemein akzeptierte wissenschaftliche Definition. Eine weiter gefasste Lesart sieht jede im Laufe des Lebens stattfindende zeitgebundene Veränderung als Altern an. Darunter fallen die als positiv bewerteten Reifungsprozesse in der Kindheit und Adoleszenz genauso wie die negativ konnotierten degenerativen Erscheinungen bei betagten Erwachsenen. Aus dieser Definition abgeleitet beginnt das Altern höherer Organismen unmittelbar nach der Vereinigung von Samen- und Eizelle und endet - nach unaufhaltsamer, inzwischen messbarer Telomerenverkürzung - mit ihrem Tod.

\section{Golden girls and bad ol' boys}

Klar ist, dass ein langes Leben in fast allen Fällen seinen Preis hat: Verlust der Autarkie, Demenz, Alzheimer, Isolation, Diskriminierung, Ghettoisierung, Armut und - bei allen Neunzigjährigen - ein Prostatakarzinom.

Als der Brandner Kaspar in der erfolgreichsten aller bajuwarischen Komödien den Boanlkramer (Tod) mit Kerschgeist (Branntwein aus Kirschen) betrunken macht und beim Kartenspielen bescheißt, gewinnt er so das ,ewige Leben“. Spätestens aber als er alle seine Lieben überlebt und nach einem Blick ins Paradies, fleht er Petrus auf Knien an, nicht in das Jammertal zurückkehren zu müssen.

Dass die Hauptpersonen einer der gelungensten Auseinandersetzungen mit dem Altern weiblich sind, entspricht durchaus den bekannten demografischen

* Johann Wolfgang von Goethe. Faust: Der Tragödie zweiter Teil. 2. Akt, Felsbuchten des ägäischen Meeres, Thales zu Proteus.
Gegebenheiten: Die US-amerikanische Sitcom „Golden Girls“ drehte sich um vier ältere Damen, die in einer Wohngemeinschaft in Miami gemeinsam ihren Lebensabend verbringen und dabei auf die unterschiedlichsten Alltagsprobleme stoßen. Blanche, Rose, Dorothy und Sophia arbeiteten viele ernste, sozialkritische und seinerzeitige Tabuthemen (Sexualität, Beziehung, Wohnen im Alter) mit entwaffnendem Wortwitz ab. Im Gegensatz zum urologischen Tagesgeschäft sind Männer hier nur Sidekicks.

Kein Happy End hat die Geschichte von Dorian Gray, der sich sehnlichst wünscht, sein Porträt möge an seiner Stelle altern. Als die Dienstboten am Ende von Oscar Wildes einzigem Roman die Leiche von Gray finden, ist sie kaum zu erkennen. Sie hat ein „verlebtes, runzeliges, widerwärtiges Gesicht“. Das Porträt dagegen erstrahlt „in vollem Glanz seiner köstlichen Jugend und Schönheit“.

Weder die im wesentlichen Evidenz-freie AntiAging-Medizin mit ihren Hochglanzbroschüren noch der spät begonnene Marathon-Lauf ehrgeiziger Führungskräfte („Dem Tod davonrennen“) feien vor dem universalen, systemimmanenten und irreversiblen Prozess des Alterns. Aus diesem Grund hat die URO-NEWS-Redaktion beschlossen, diesem „Phantom“ einen Schwerpunkt zu widmen. Eine lebensabschnittsgerechte medizinische Versorgung kann dabei helfen, die Angst vor dem Altern abzubauen: Indem die Aufmerksamkeit dafür geschärft wird, dass Reifungs- und Ökonomisierungsprozesse in unserem seelischen System die Verluste an grober körperlicher und geistiger Kraft durchaus ausgleichen können - auch der Herbst hat noch schöne Tage!

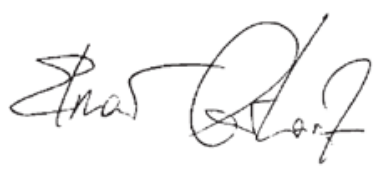

